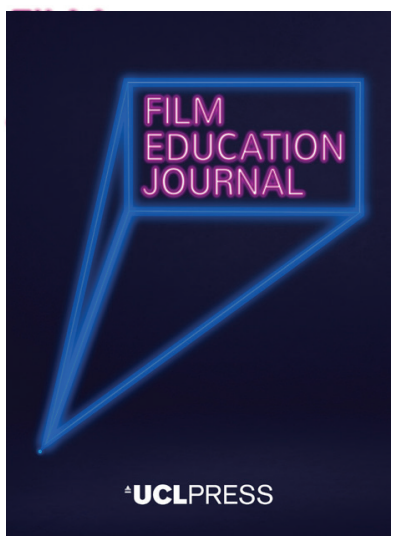

UCLPRESS

FILM EDUCATION JOURNAL

ISSN 2515-7086 (Online)

Journal homepage:

https://www.uclpress.co.uk/pages/film-education-journal

\title{
Exploring the place of animation and the role of the classroom-based film-maker within a wider field of Scottish moving image education
}

Robert Munro iD and Jonathan Charles

\section{How to cite this article}

Munro, R. and Charles, J. (2021) 'Exploring the place of animation and the role of the classroom-based film-maker within a wider field of Scottish moving image education'. Film Education Journal, 4 (1), 71-85. https://doi.org/10.14324/FEJ.04.1.06

Submission date: 21 September 2020

Acceptance date: 13 November 2020

Publication date: 10 June 2021

\section{Peer review}

This article has been peer-reviewed through the journal's standard double-blind peer review, where both the reviewers and authors are anonymized during review.

\section{Copyright}

(C) 2021 Munro and Charles. This is an open-access article distributed under the terms of the Creative Commons Attribution Licence (CC BY) 4.0 https://creativecommons.org/licenses/ by/4.0/, which permits unrestricted use, distribution and reproduction in any medium, provided the original authors and source are credited.

\section{Open access}

The Film Education Journal is a peer-reviewed open-access journal. 


\title{
Exploring the place of animation and the role of the classroom-based film-maker within a wider field of Scottish moving image education
}

\author{
Robert Munro* - Queen Margaret University, UK \\ Jonathan Charles - Film Education Practitioner, East Lothian, UK
}

\begin{abstract}
This article explores animation as a popular mode of moving image education in the wider field of Scottish film education, through a discussion with film education practitioner Jonathan Charles. It reflects on Jonathan's pedagogic approach to film education, the way in which it is shaped and aligned with changing institutional and funding imperatives, and the affordances of animation, through a detailed look at a film-making project with a primary school in West Lothian, Scotland. It reflects upon the challenge to maintain in-depth film experiences for young people, with training and working with teachers to allow film experiences to be scalable and multiply to reach a wider range of young people. The article also discusses the drive to give young people agency throughout the film-making process, and how film education practitioners and teachers can best facilitate that.
\end{abstract}

Keywords: animation, film in the classroom, primary school, film literacy, Scottish education

With the lowering costs and technical developments of digital technologies in the 1990s, animation has become an increasingly viable form through which to explore practical film-making in schools. Free of many of the issues and constraints facing live action film-making with young people in school settings (such as the complicated permissions required to film children, and the contingencies of weather and location when filming outside school), animation offers the opportunity to introduce young people to basic elements of screen practice - often in an abstract, imaginative and creatively liberating manner. Greater feasibility may not be the only affordance of animation for foundational film education, however. Writing in the pages of the Film Education Journal, Volker Pantenburg and Stefanie Schlüter (2018) have drawn on aspects of child psychology in exploring children's propensity for avantgarde experimental film, exploring abstraction at a point in life when learners are unencumbered by the systematizing perspectives of adulthood. Pantenburg and Schlüter (2018: 117) argue that 'adults, when looking, are always eager to synthesize picture puzzles and thereby solve them', rather than approaching perception as an '"endless mishmash of beginnings", "an accumulation of baffling picture puzzles" from which the "emotion of an enigmatic perception" derives' (quoting Genazino, 2007). Children, in the absence of such systematizing impulses, may thus be more open to the shifting forms and untethered significances of experimental film. Similar arguments could be made for children's aptitude for animation, whose simultaneously 
material and immaterial nature - whereby forms lack rigid definition, possessing the potential to shift and transform - may also serve to capture and articulate the relatively untempered mutability of children's imaginations.

Whether for reasons of feasibility or the complex resonances and affordances it may create for children's imaginations, animation has become an increasingly popular choice for film education projects with young people across Scotland, both in and outside classrooms. At the time of writing, a notable number of Scottish film education projects - among them Screen Argyll's Animated Argyll and Animated Tiree, alongside the work of animator Sharon Sorensen with Screen Education Edinburgh, and that of Jonathan Charles and D Fie Foe, as explored in this article - are using animation as the primary means of moving image education with young people in diverse learning environments. Educational resources offered online by the Scottish Government's education office note that 'developing animation skills is growing in popularity, particularly in primary schools... [and] can be developed and used across several areas of the curriculum' (Education Scotland, 2021).

As a small nation, currently negotiating complex aspects of autonomy within the wider body of the United Kingdom, Scotland's relative lack of a film culture has been continually bemoaned over the past four decades by a series of commentators (see McArthur, 1982; Cousins, 2006; Petrie, 2014; although Murray (2019) argues that at times this argument is overstated). As has been argued elsewhere in the pages of this journal (Chambers, 2019), film education is thus frequently approached as a potential means of addressing Scotland's difficulties in establishing a viable organic film culture. The past few decades have seen considerable changes in terms of the institutions tasked with overseeing the development of film education in Scotland. In 1997, the national body Scottish Screen was formed, as an amalgamation of pre-existing organizations such as the Scottish Film Council and Scottish Film Production Fund. In 2010, Scottish Screen was itself amalgamated with the Scottish Arts Council into the wider body of Creative Scotland, to the concerns and opprobrium of certain film industry voices concerned that film would suffer without a dedicated body (IPS, 2015). Most recently, a new body, Screen Scotland, was founded in 2018, as a semi-formalized entity within Creative Scotland, tasked specifically with overseeing the needs of Scotland's screen sector. Alongside these developments, from 2015 to 2018, a specific and short-lived organization - Scottish Film Education - was set up specifically to oversee core aspects of film education funding and provision within Scotland.

This article frames the work of film education practitioner and animator Jonathan Charles within the wider context of film education in Scotland over the past decade. In writing, we draw both on Jonathan's perspective and experience of delivering the project in question and school-based animation work more generally, alongside Robert Munro's broader perspective across approaches to film education both in Scotland and further afield. While the majority of this article is written in the collective voice, in places we have chosen to use direct quotations in order to allow Jonathan's voice to speak more directly of his experiences working with animation in the classroom.

Overall, this article seeks to explore some of the particular affordances that animation may generate as a means of film education with young people in Scotland, and the role of the film educator in facilitating this. In order to do so, we place a case study of an animation project led by Jonathan at Harrysmuir Primary School in West Lothian in 2019 within a wider landscape of film education provision across the country, in particular the 'cluster model' recently pursued by the now discontinued body Scottish Film Education. Recalling the imperative placed by Bachmann and Zahn (2018) upon examining the ecological contexts of film education, we argue that considerations of 
film education in Scotland are inextricable from the shifting institutional geographies and subsequent changing priorities with which they are entangled, and we therefore argue that consideration of changing practices on the ground must be placed within this context. Thus, while seeking to draw out the particularities of animation as a form of practice in schools in Scotland, this article also explores how such projects have been shaped by changing institutional priorities. We argue that Jonathan's work at Harrysmuir highlights an emphasis from the funding body, Screen Scotland, on widening access to film education opportunities in Scotland by lessening the reliance on the presence of a film-maker in the classroom, and instead aiming to empower and upskill teachers in a range of moving image practices. In what follows, we first explore the place of animation within film education more generally, before presenting a case study of Jonathan's work at Harrysmuir, which 'zooms' from the wider picture of Scotland's film education landscape (and in particular the 'cluster model' that has underpinned much publicly funded film education work over the past five years) to a close-up upon Jonathan's work with teachers and young people in the classroom.

\section{Animation and film education}

Animation has become a central aspect of the increasingly digital experience of moving image education for young people in Britain. As Fleer (2018) discusses, animation has also become central to the digital childhoods of pre-school children, allowing for complex social and cognitive development in free play spaces. Discussing animation as a 'semiotic process', Burn and Durran (2007) describe how digital media tools allow for the iterative development of work (an aspect of media practice not limited purely to animation). As Jonathan describes below, the shift to digital in film-making broadly, and animation in particular, has allowed for greater iteration in the editing and reshaping of work as it progresses within film education projects, in a manner not dissimilar to that in which the written form may be subject to iterative editing and reworking.

Animation also offers a freer representational mode than live action. The continually recording camera captures events moving in real time, and in real places a Bazinian 'ontological' realism. In contrast, animation does not capture the movement of objects at a distance, independently. Rather, the movement takes place as a result of the image-making process itself. One might counter that in live action film-making, movement does take place as part of the 'image-making process': the actor has to move to a mark in the foreground of the frame as set by the director; the camera similarly moves in a manner dictated by the cinematographer and director, and so on. There is, however, no essential inertia to the objects being recorded: the tree in the background of the shot sways in the wind whether the camera is recording or not. In animation, the freedom is then to choose how (or if) to represent reality. Any backdrop the children can imagine can be created through paint, drawing, cut-out card and/or digital software. Characters or objects can move in ways that defy the laws of physics. As Fleer (2018) notes, discussing a project using tablets for animation with children, the processes involved in digital animation allow for a playful 'what if' process. Recalling Burn and Durran's (2007) discussion of iteration, Fleer (2018: 955-6) argues that even in very young children, this iterative, 'what if' aspect of digital play allows for a complex development of skills in three pedagogical areas. First, it shows the deliberate nature of children's choices, who in Fleer's project were restaging fairy tales. Here, the processes of storyboarding and object movement highlighted how their explicit choices were related to story structure. Second, as Jonathan discusses below, the process promoted 'self- and other-regulation' in the children, in how they organized and completed the 
animation. Third, as the story elements were already there, it was clear to the children how the digital technology acted as a facilitator tool with which to turn their versions of a story - expressed and refined in free play scenarios - into actuality.

Similarly, Jonathan discusses the move from tape-based animation equipment in the mid-to-late 1990s as a 'revelation':

The thought of filming and editing completely digitally made me nervous in the beginning, but it was a revolutionary point for animation. Aardman [Animations, a leading British animation company] made that jump too, which gave the process greater legitimacy. It was revolutionary for animation at that point, because you could see your work back immediately: now we take that for granted, but this was unique. With the video system you would wait 15 seconds and then watch it: you had to wait 15 seconds between every frame. Before that, when shooting on film, you might have to wait days before seeing what you shot. For the first time ever, people were able to change per frame what they were doing, and see if they were making a mistake. It was an exciting moment, I think.

While the increasing ubiquity of digital technologies capable of creating, editing and distributing moving image forms thus offers considerable affordances for moving image education, an overreliance on the immediacy offered by mobile phones and tablets also arguably has it pitfalls. Potentially endless digital iterations, untempered by material limitations, may risk undermining the craftsmanship involved in moving image production, whether animation or live action. When celluloid film stock was precious and expensive - a tactile, malleable form - there was a greater emphasis on pre-planning, of setting up a frame with careful consideration, and ensuring all elements in the frame were positioned in order to create a compelling mise en scène before the risk of committing the image in front of the camera to celluloid. With the ability to instantly replay a shot, analyse it in slow motion, swipe delete and redo a take without consequence, however, there is a resulting risk of images becoming more disposable. Is there a danger, then, of losing that respect for the crafting of the image?

While seeking to preserve the artisanal values of the craftsperson (a central tenet of the Spanish film education project Cinema en curs (Correa, 2020)), it would equally seem important to avoid elitist perspectives privileging a cinephilic vision of the past over the moving image culture so ubiquitous within the daily lives of young people today. Rather, there would seem to be a delicate balance between facilitating the learning of young people within the respective crafts of moving image media, and encouraging their own agency, their own creative and imaginative first impressions, untethered by the expectations embodied within a particular canon of cinema. Jonathan states that:

There's no right or wrong in film language. There's that same thing with YouTubers, they sit in front of the camera and they're a bit more George Méliès. Everything has to happen in front of the camera, which is interesting. I think what I'm trying to do, and what we are trying to advocate, is to say let's use that pre-learned knowledge from TikTok, YouTube, Instagram, etc. that they have gathered, and embrace and welcome it, rather than querying its value.

In this sense, contemporary moving image culture today perhaps resembles the origins of cinema. What Gunning (1990: 64) describes as the early twentieth-century 'cinema of attractions' privileged non-narrative forms and instead 'sees cinema less as a way of telling stories than as a way of presenting a series of views to an audience, fascinating 
because of their illusory power'. This is a cinema embodying an exhibitive relationship between the creator and the audience, rather than one presenting an illusion of life, albeit narrativized, unfolding unmanipulated before an audience. For example, Sarah Cooper's (2020) recent performative miming of US President Donald Trump, filmed on TikTok, performs a similar exhibitionist 'trickery' to Gunning's (1990: 65) early cinema of attractions, and to Jonathan's referencing of Méliès's famous 'magical attractions'.

Similarly privileging the prior experiences and knowledge of young people, Jonathan tends to embrace the freedoms of expression afforded by animation, particularly in the early stages, and in terms of the abstract potential inherent in the medium:

You sometimes need to form that scribble into something, and you need to have that - it's a truism - there is a stage that happens - and lots of teachers have mentioned it to me - in terms of art, where kids lose that fluidity that they had as a child. They lose that naivety of expression. And that's the balance, trying to not be so prescriptive with your tuition so that they lose that passion and childhood brilliance.

Here we can draw parallels with the emphasis on play, both in the Scottish Curriculum for Excellence, and in educational theory more broadly (for example, Fleer, 2018). Recalling Pantenburg and Schlüter (2018), we could speculate as to the value of a film education that might seek to encourage experimentalism and allow children opportunities to continue exploring abstract parameters of expression, and partially postponing the move onwards towards more traditionally representative images. For example, the experimentation of the children's early animation sketches, whether through pencil, cut-out shapes or plasticine forms, is in a sense validated by Jonathan's showing of clips from the famous Scottish animator Norman McLaren, whose melding of abstract animation with sound proves enduringly influential. Jonathan also frequently uses pixelation in his work, a form also pioneered by McLaren. This would correspond with Pantenburg and Schlüter's (2018: 122) argument for an education in film that is imagebased; an education that does not immediately foreground language, but instead uses images as both the object of study and the subject and instrument of teaching.

\section{Harrysmuir Primary and Scotland's 'cluster model'}

Before turning to our case study, we - recalling Bachmann and Zahn (2018) - seek first to establish the wider context in which Scottish film education projects take place. At the time of writing, the primary source of funding for film education projects in Scotland is through Screen Scotland's Film Education Partnership Fund, launched in 2018. Drawing from an annual budget of $£ 300,000$, the fund supports projects adopting a collaborative approach to film and moving image education, between a diverse range of partners, such as schools, libraries, universities, cinemas, film-makers and charities. The desire for a collective approach to film education here seems to arise both as a recognition of the value in affording agency to those on the ground, and a desire to move beyond the siloed approaches remarked upon by other contributors to the Film Education Journal (Chambers, 2019: 35-6), wherein organizations and individuals work in isolation, without tapping into the cumulative knowledge and experience of those working elsewhere across (and beyond) Scotland.

The Film Education Partnership Fund replaces the now defunct Scottish Film Education, a short-lived organization that existed between 2015 and 2018 overseen by Scottish Film Ltd, a consortium of Scottish cinemas, film festivals and the cinema 
development agency, Regional Screen Scotland. Working in collaboration with Into Film (themselves funded by the British Film Institute), Scottish Film Education was responsible for the Scottish 5-19 film education programme, wherein a number of film and moving image practitioners (including Jonathan) were tasked with providing career-long professional learning (CLPL) opportunities for Scottish teachers, as well as in-class film-making workshops with young people.

As stated in Scottish Film Ltd's submission to the Scottish Parliament's Education and Culture Committee in 2015, Scottish Film Education's 'cluster model' sought to offer a locally 'integrated approach to Continuing Professional Development within individual clusters of schools' (Donnelly, n.d.: 3, emphasis in original), seeking to create around ninety 'clusters' across Scotland. As with the Film Education Partnership Fund, the emphasis here was upon working within existing areas of expertise and organizational structures, rather than inventing or duplicating them. The cluster model involved establishing a central focus for film education within a secondary school and its feeder primary schools, aiming for a ripple effect to facilitate the sharing of knowledge and expertise between teachers and children in the local area. Film education practitioners such as Jonathan - would then be asked to share their expertise with teachers from the cluster, principally through CLPL sessions (with the possibility of limited classroom activity following these). Priority was here placed upon equipping teachers with the knowledge and resources to deliver film education sessions in their classrooms themselves. In this respect, the cluster model can be seen partially as a response to Creative Scotland's ongoing imperative for public funds invested in film education to reach the greatest number of participants; the intention being that film education disseminated in this way - through interlinking webs of different schools - might have the widest possible impact. While Scottish Film Education no longer operates, the cluster model, and the film-making practitioners involved in facilitating it across Scotland, remains an ongoing component in the provision of film education across the nation. Harrysmuir Primary School in West Lothian formed part of the Inveralmond High School cluster, with whom Jonathan has worked for a number of years. Reflecting the cluster model's emphasis on interconnectivity, a priority to date of Jonathan's film education work more generally has been exploring how film education projects may help foster cohesion within broader communities. Elsewhere in Scotland, Jonathan facilitated the creation of a film about the transition from primary to secondary school in Musselburgh (East Lothian) between seven different primary schools, a production overseen by the cluster's secondary school, who ultimately hosted a screening of the final film for all involved. Here, the secondary school served effectively as the producers of the film, with the primary schools each adopting different roles in pre-production and production stages, such as writing, storyboarding, location scouting, principal photography, set and costume design, editing, sound design and so on.

Following a similar logic, it was decided that Harrysmuir would make a film about a problem that Inveralmond High was experiencing with students smoking in certain areas around the school. Rather than a hectoring anti-smoking film, the animation was intended to encourage students at the secondary school to think about the areas in which they smoked, and how that affected others. The idea for the film came from Inveralmond's students, rather than Harrysmuir's, and Jonathan describes the tension between using film to support aspects of experience already present in schools, and encouraging the organic and autonomous development of something new:

Do you go with a topic led by something that is already happening in that space, or do you bring in a totally new film project? I think now, because we are encouraged by funders to hand over the reins to the teacher, it is 
more valuable to try and find out what their topic is, and see if you can work out together a method for making a film with that project.

This arguably reflects a perennial difficulty for film education practitioners, between fitting film into the curricular and educational priorities of individual schools and classes, and encouraging autonomy and agency in young people to approach film afresh, within the context of their own lived experiences. Here the question of agency is important, recalling Chambers's (2019) discussion about the ethical and moral grey areas of co-creation, whereby one considers the boundaries between the teachers, film-makers and institutional frameworks required for the facilitation - and sometimes competition - of film-making projects and the voice of the young people as filmmakers themselves. Similarly, Alves and Pereira (2020: 28) note the temptation for these boundaries to be crossed in their consideration of a high school film-making project with teenagers in Portugal: 'teachers were sometimes tempted to solve these struggles and difficulties, overstepping students' creative freedom and compromising their autonomy in problem-solving and decision-making'. At Harrysmuir, students were given the autonomy to decide on what angles they would pursue within the brief they had received from the secondary school, in making a film highlighting the problem of smoking in areas of the school. Working with two class teachers, Jonathan had to then carefully navigate through the production process to shape the final film on an executive level, encouraging certain narrative lines at the expense of others. The students worked in groups to each come up with their own segment for the film, which they would write, storyboard, film and edit themselves. These segments were then collated and knitted together by the classroom teachers, with some final support by Jonathan, limited to small editorial touches.

Having previously worked with Jonathan on a live action film project at Harrysmuir, one of the classroom teachers was confident, knowledgeable and motivated in using film in the classroom, and his students thus already had a degree of understanding and confidence. While the other teacher was newer to the film-making process, Jonathan notes that she 'grew significantly in confidence throughout the project'. In keeping with the emphasis within the cluster model on passing on film education skills to the teachers themselves, and given Harrysmuir's professed interest in exploring animation after their earlier experiences with live action film-making, Jonathan first ran a CLPL workshop on animation with teachers at the school in a 'twilight session' (outside school hours). While Harrysmuir is well equipped with iPads, it is worth noting the divergence in schools across Scotland between schools that have limited access to hardware such as tablets or cameras, and local authorities who have opted to 'buy in' relatively wholesale to the equipment provided by a particular brand of technology. For example, East Lothian local authority has embraced Google tablets, as well as the Google Classroom platform, while the City of Glasgow local authority has signed a deal with Apple to ensure that every student has access to their own iPad (BBC, 2019). To this end, Jonathan keeps his approach to teaching animation relatively prescriptive, adapting to what Bachmann and Zahn (2018) would call the 'conditions of practice' encountered in schools, where tablets are becoming ever more embedded into children's personal and educational spaces. Jonathan encourages the use of the Stop Motion Studio app, created by Cateater Software, for both the simplicity of its user interface, and its potential to offer more complex functionality if desired. Considering the use of particular equipment, Jonathan notes:

I really discourage teachers from using a stills camera and taking photos and then using that to build an animation, because the joy of digital 
technology is the immediacy of playback, and how much more you can learn about animation during the filming process.

After the twilight session at Harrysmuir, which involved demonstrations of the Stop Motion Studio software on the iPads that the teachers would use in class, Jonathan had a full day in the teachers' respective Primary 6 classes (Primary 6 in Scotland is composed of children between the ages of 9 and 11, their penultimate year before starting at secondary school). Jonathan outlines that process in detail:

Essentially, on that first day I try and get them to do a first animation exercise, the moving of simple, cut-out shapes of coloured card, across a white paper background. It's very prescriptive. At Harrysmuir, they had tripods for the iPads, which is a huge benefit. You create a workstation, where the tripod and iPad is set up, so it doesn't move, and it's parallel to the desk with the paper on it, shooting down vertically, a birds-eye-view of this 2-D scene. If the school doesn't have tripods, or won't invest in some, you have to be creative. You can fix the iPad to a desk, using tape and Blu-tack, and move the paper and cut-out card lower down to the floor. Of course, it's not as stable, but it is certainly an improvement on handheld set-ups.

You then rotate through everyone. Rotating through a class of thirty and getting them to all have a go on one device at the front of the class is hard. But it's a very, very valuable thing to do. If you can actually get it so that the children are seeing what's happening, so that they're noticing how the onion skinning works. Onion skinning is where the software retains a ghost of the previous image you have taken a frame of, so that when you move the shape slightly in a different direction, the previous position is retained on the screen; think of it like the trail a snail leaves behind. That way, you can keep a consistency in how far and how quickly you move the shapes. They're getting an idea of how it works before they go and work with the device.

Then you get them into groups, get them all if possible, working on a device. So in a class of thirty, if you can have five or six iPads, meaning groups of five or six young people. You're again trying to encourage just shapes, mainly because of speed. We had worked with them for an hour with our introduction, and you've tried to get all those kids to create something quickly in their groups, and you've maybe only got an hour or two left. They're not trying to create anything epic, just working with those shapes. But sure enough, that's when the kids of some groups will have done bouncing shapes and a more abstract thing, others will have turned their three or four shapes into something else. There are no rules really, they're all utilizing that pre-learned knowledge, or making it up.

After experimentation with the software, Jonathan moved on to a more detailed look at design and crafting processes in animation. Here, Jonathan showed the children how to create basic puppets, how to create joints for movement, how to experiment with different backgrounds, and how they need to be fixed down for the scene. After this first day in the classroom, Jonathan left the teachers to get on with helping the children to plan and create their short animations. Jonathan continued to provide support remotely, communicating with the teachers via email to help clarify a process or offer a suggestion on the work as it was progressing. Here, reflecting a high-level 
imperative from funders, we can again see the desire to empower teachers with the skills and knowledge to become film education practitioners in their own right.

Returning to the classroom for a second visit, Jonathan facilitated sessions in which the students shared their work in progress, both with him and with each other. Here, recalling Chambers's (2019) discussion of co-creation, Jonathan might be framed as a producer viewing the rushes and offering feedback:

Each group had to go through the 'pressure' of having their animation shown. I had to - or together as a class - always give two stars and a wish. You can criticize kids if you find something good in their work as well. That helps them see value. Obviously, that's a very important stage. In their groups they then went off and improved their work based on the feedback from that session.

Here, Jonathan and the teachers oversaw the students' developing work as part of a cocreative process, offering iterative feedback, and in some cases adding little touches to the final film in the editing process. Two of the students proved very proficient at working with iMovie, allowing an opportunity for peer learning, whereby stronger students could sit and assist other students to get to grips with the editing stage. A notable aspect of the project was that ultimately all of the filmed animation appearing in the finished film was done without Jonathan present. Between two different Primary 6 classes (roughly fifty or sixty students), the children and teachers undertook all the production work, with Jonathan's support restricted to the pre-production stage and a small amount in post-production. Indeed, one of the most positive outcomes for Jonathan throughout the project was witnessing the teachers' growing confidence working with film, not only because of his support but also, crucially, because they were learning from the children, whose previous experience using iPads for live action proved invaluable. This again reflects the high-level imperative (as encouraged by funders) for film education to take place without the film education practitioner present: here the film-maker's job was to plant the seed and nurture it in its early stages, before subsequently letting it grow and bloom on its own terms through the work of teachers and students. When the project was completed, the film was shown at a celebration screening within the school, to which parents were also invited; for students at Inveralmond Community High School; and, finally, at the Scottish Parliament. The completed film, which adopts a portmanteau structure, features 13 vignettes around the theme of discouraging smoking near children, particularly around school gates. The sections of the film are all two-dimensional, stop-motion animations, using cut-out paper. What is particularly evident in the completed film is the relationship between the freedom that animation allows in imagining the impossible, and the tethering constraints of narrative or messaging. Many of the film's sections look at some of the consequences of smoking and related littering, such as 'Strike!', in which bin collectors refuse to keep clearing up cigarette butts. Repeated intertitles of 'next day' find the young people becoming progressively lost in the litter. Elsewhere, 'Bike to school' looks at the extended trip to school a boy has to make on his bike to avoid the smokers, causing him to be late for school. There are also sections which adopt a less literal, more playful approach to the same topic. 'Lost dog', as the title implies, shows us an owner losing their dog in a fug of smoke, and - once reunited - somersaulting through the air. 'Pyro cat' imagines a large cat accidentally consuming another littered cigarette butt, turning red, breathing fire and warning viewers to 'Be careful with your cigarettes' (Figure 1). The playfulness and ingenuity of the children's imaginations are matched by the craftsmanship of the animation, particularly regarding titling. 'Icy smoke' is particularly inventive in this 


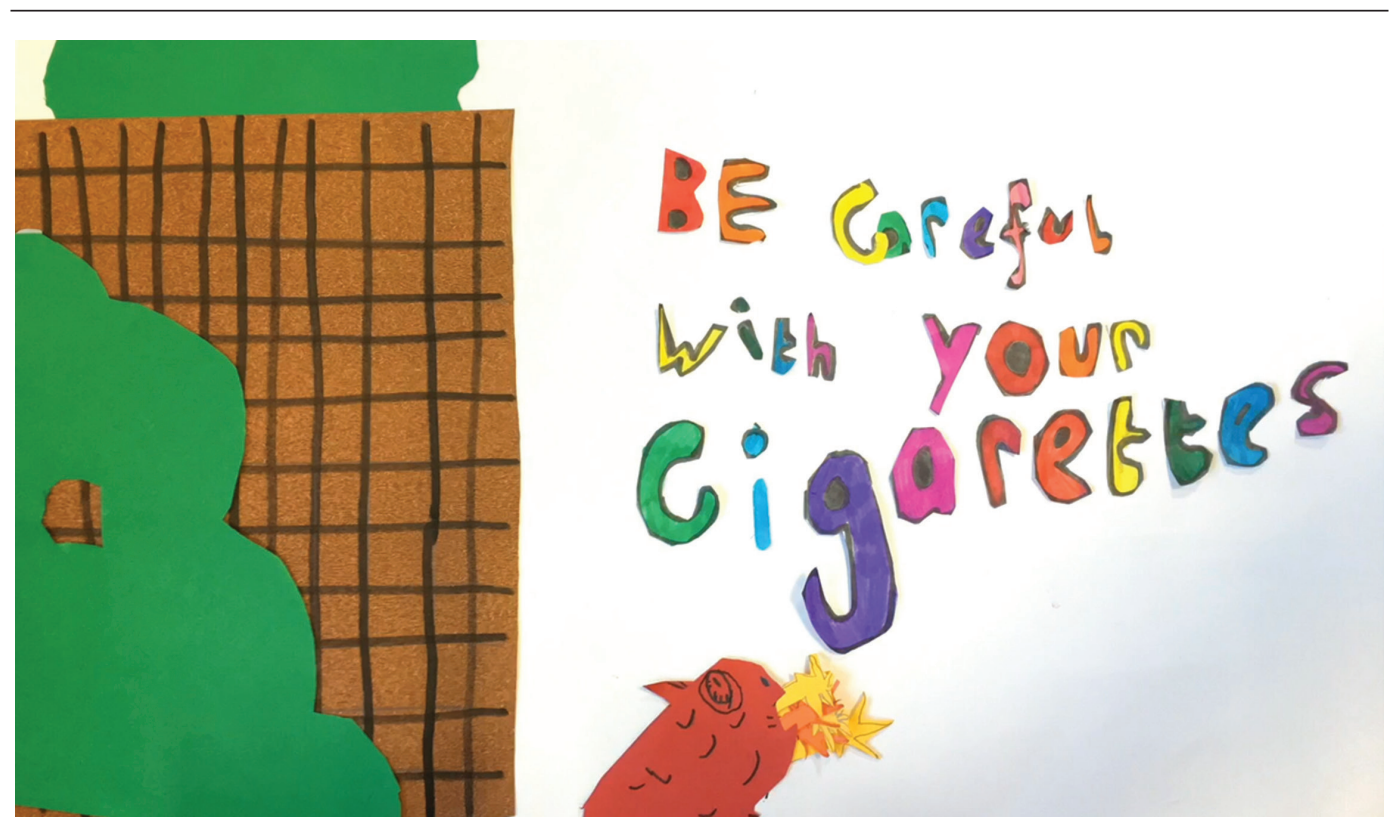

Figure 1: 'Pyro cat', Harrysmuir Primary, 2019 (source: author)

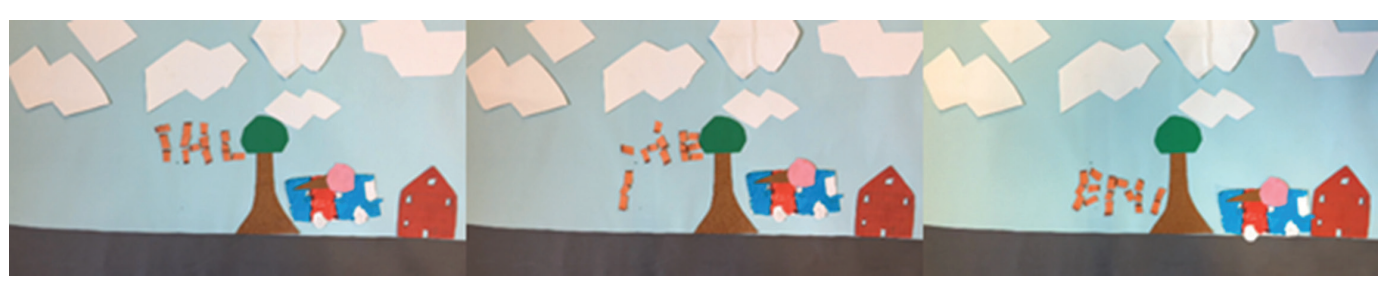

Figure 2: 'Icy smoke', Harrysmuir Primary, 2019 (source: author)

respect, with stray cigarette butts rising from the ground to sequentially bring up 'The End' on the screen. With too few butts to write the words in full, the cigarettes dance up from the ground and start rearranging into the letters, before leaping from the beginning of the words to the end to continue the 'writing' in a sort of Mexican wave (Figure 2).

Reflecting upon the project after its completion, one of the aspects that particularly interested Jonathan was the way in which moving image education here centred upon animation - served to subvert the settled dynamics of the classroom. As Bergala (2016), Borčić (2020) and Daly et al. (2020), among others, have noted, the facilitation of dialogue, through open questioning of young people after watching films, often produces surprising results, highlighting the active literacies of young people who perhaps struggle with traditional reading and writing literacy activities. For Jonathan, this is one of the biggest benefits of working with film in the classroom:

It's always been a blessing that I've been able to go in and work with a medium where you don't have to convince kids that it's interesting. And that anecdotal adage is true - kids that don't engage in other literacy scenarios definitely open up and get involved, for both making film and for reading film. For children who might struggle with the written word or reading, there is definitely an improved engagement with film criticism. Numerous teachers have said how the kids who normally don't talk in class 
are now talking. Once they switch on to film there's another set of kids who are maybe less confident or don't feel they've got a skill or don't feel they're clever, they suddenly realize: 'hang on, I'm good at this!'

The opposite, it seems, can also be true, in that children who might be confident in traditional literacy activities often find themselves experiencing uncertain new terrain:

There are some children, of course and often they're the confident ones, that can suffer a knock in confidence because they're surprised that they're not the best at it. Teachers spot it quite quickly, and as an educator going into the classroom, you have to be aware. 'Hang on, that kid seems to be stepping back. Why is that?'

The power that film seems to possess in changing classroom dynamics feeds into Jonathan's desire to ensure a democracy of access within the class with which he and the teachers are working. How does one ensure - given a class of 25 or 30 young people and only an hour or two to work with them - that everyone gets a fair shot at learning what they might be best at in terms of the different roles in the film-making process? As Jonathan describes:

It's one of those tensions in the film-making process. Do you try and give everyone an equal crack of the whip - does everybody have a go at sound recording or holding the camera? I'm slightly torn. There are certain filmmakers who go in and establish the roles. And teachers as well, they set up all the roles. That's fine. That works. It's probably going to work more quickly and get things done. But it can be undemocratic, and not necessarily the best way of working, and not the best for children.

For example, one of the early animation tasks I always use is moving coloured cut-out shapes on a white background. It's really to get them moving away from representational forms and getting them to think in the abstract. So, you might have a purple circle, a green square and an orange triangle. And with each frame you move each piece slightly to produce stop-motion animation. You decide beforehand that the purple circle is going to move the quickest in an erratic direction. Maybe the orange circle moves slowly at the bottom, like a ball rolling. Eventually they usually move towards the representational: 'if you put that circle on top of the triangle, it's like a head and body', but we try to encourage the abstract in the beginning.

It's sensible to encourage - not dictate! - just one person to control who's taking the frame. You try and keep that person in that one role throughout that three-second shot. Because that is a sensible division of labour and skills. Yet, when we do our very first intro exercise, which the teachers can do as well, we rotate everybody. We let everyone have a go at pressing the record button. Everyone wants to press it and hear the click or the ping. What we've realized is, and this is part of what I'm working on at the moment, the first exercise, when everyone is allowed to press the record button, you really focus on the movement that you are putting into your shapes that are under the camera. So, when a new person takes over the camera and that shape, they don't just go 'Hey, I'm moving the triangle.' You say: 'I am moving the triangle slowly in an upwards direction.' The last person passes on that information. 'I am moving the triangle $2 \mathrm{~mm}$ 
upwards.' When you see this test that you've tried to bash out and given everyone a chance to go, when they watch that animation, it's not a heap of rubbish. So, at the same time as learning the roles, you're also learning animation techniques.

As mentioned above, peer learning has become a central part of Jonathan's approach to film education with young people, supporting a desire to empower students to make their own decisions and learn from one and other, while also freeing up teachers to facilitate, rather than becoming overly involved in the technical aspects of using equipment. As Jonathan describes:

It saves the teachers time and it's something that I was nervous about in the olden days. It's crucial that you, as a teacher, allow kids that are more knowledgeable than you to help you out if possible. It's then a case of you teaching them how to teach. When kids edit, three or four of them sit around an editing device and the person who knows the most sits in the middle and they control the software. And that is no good. Your job as a teacher is then to say, OK, this is the editing set-up. You distribute the strong IT kids around those groups, hopefully. But when it comes to the edit, because they're sitting in the class or, hopefully, nearby, your main task is to make sure that no one is hogging the editing process. You're getting different kids to sit in the middle position, you encourage them to change chairs so that there's a different person in the middle, so the weaker person sits in the middle of the edit process and the adviser then sits to one side. In the old days, I used to pick up the mouse and do it for them. If you never pick up the mouse, if you never do it for them, and you don't allow that more knowledgeable peer educator to reach over and change the setting on the device. If you let that kid who's in front of it control it, they will learn how to do it. They'll keep making a mistake, twice, three times, but eventually they will get it.

\section{Conclusion}

This article has sought to place the work of film education practitioner Jonathan Charles within a number of overlapping contexts. The animation project at Harrysmuir Primary School in West Lothian ran for four weeks, with Jonathan visiting the children twice. The approach illuminated by this case study thus highlights the ways in which as part of the cluster model then favoured within film education in Scotland - the role of the film education practitioner is as much about educating and upskilling teachers, and indeed probably more so, than it is about working with children in a more direct capacity in the classroom. It serves as an example of how confident teachers can bring to fruition a successful film-making project with their class, with light-touch supervision from a film-maker. In this sense, learning is perhaps focused on the broader cognitive and social skills that the film-making process facilitates, rather than a film education focused on relaying aspects of cinema history or uncovering different cinematic forms and practices. That said, the focus on animation, Jonathan's particular area of expertise, speaks to a cultural moment in which young people's familiarity with digital technologies and software offers an easy point of access to film education for educators and young people alike.

Since 2015, the cluster model has played an important part in trying to achieve Scottish Film Education's initial stated objective 'to ensure that every child and young 
person has access to film and moving image learning experiences: by increasing reach, depth and inclusivity of provision, including currently under-served communities across Scotland' (Donnelly, n.d.: 1). Alongside this is the logic that an approach to film education reliant on the presence of film-makers in the classroom might not always offer the increased reach and inclusivity of provision detailed above. Such an approach as Chambers (2019) has highlighted - is also frequently vulnerable to tightening economic constraints, relying on resource-intensive approaches to film education (even if these may offer a greater depth and quality of experience). A central part of Screen Scotland's approach in this respect, through the work of film education practitioners such as Jonathan, is therefore to provide quality training opportunities for teachers over a prolonged period of time. By working within the same cluster of schools for a number of years, film education practitioners can offer repeated training opportunities for the same group of teachers. Such sessions can also facilitate the sharing of best practice, and discussions about how teachers may accommodate film education activities both within the curriculum and within their own professional practice. Once teachers become convinced of the benefits of film education, and how it can complement existing curricular school work, then - it is hoped - opportunities are created to widen the reach and scale of provision through teachers actively embedding film education within their wider pedagogical approaches in the classroom. Rather than film education being seen as one-off, 'special' projects facilitated by outside experts who may only appear once during a child's time at primary school, there becomes greater possibility for film to become more integrated within their education experience. This, of course, runs the risk of containing and associating film within formal educational frameworks, diminishing the prospect of Bergala's (2016) conception of the disruptive potential of the outsider passeur, encouraging individual, unique experiences with film for each student.

Set within the broader framework of the cluster model, Jonathan's experiences at Harrysmuir arguably point to a central tension within Scottish film education, between - on the one hand - a desire for the rich, detailed and expansive involvement of film-makers in classrooms over a sustained period of time to facilitate 'creative, critical and cultural' (BFl, 2015) engagements with film, and - on the other hand - a desire for less detailed and intensive engagements available to a significantly wider range of young people. An obvious approach to tackling the latter is thus - as was the case at Harrysmuir - to upskill teachers and encourage their own adoption of film in the classroom. However, teachers are frequently under significant strain in terms of working with localized school and curriculum demands (particularly at secondary level), and such an approach thus relies to a significant extent upon the goodwill and passion of teachers in engaging with such opportunities. It is worth mentioning, however, that when presented with compelling evidence of the ways in which film can successfully be incorporated into the curriculum, it is the experience of both of us that teachers frequently become impassioned by its potential.

With around two and a half thousand primary and secondary schools across Scotland, it is clearly a challenge to find a middle ground between these two approaches: one which privileges in-depth, experiential relationships with the world of cinema and uninhibited creativity in the production of short films with a relatively small group of young people, and another which privileges access to what are likely to be less detailed engagements with film across a much wider range of young people. In this sense, this article forms part of ongoing dialogue in Scotland, as elsewhere, between these two approaches. Given the rapid pivot to online learning that much of Scotland, as with many other parts of the world, has experienced in response to the 
COVID-19 pandemic, research remains to be undertaken as to how distance learning, facilitated by online technologies and accessible teaching and learning resources, might help to begin to bridge this divide.

\section{Notes on the contributors}

Robert Munro is Programme Leader in Film and Media at Queen Margaret University. Robert's research investigates film-making and film education in Scotland. He has recently co-edited and contributed a chapter to Intercultural Screen Adaptation (Edinburgh University Press, 2020), and has also co-written a chapter on Whisky Galore! in the forthcoming European Film Remakes (Edinburgh University Press, 2021). His most recent article, 'Performing the National? Scottish cinema in the time of indyref', was published in the Journal of British Cinema and Television (2020).

Jonathan Charles is an animator and film-maker whose work combines animation, computer-generated imagery and live action. His company (www.dfiefoe.co.uk) has delivered many education projects for young people, enabling them to make highquality films and apps. He produced films for London 2012, which were screened at the Olympic handover celebrations, and recently made Glasgow Pixillated for Glasgow City Council's European Championships, using the 'pixelation' technique. He also directs commercial projects and develops apps (www.hippotrix.com/).

\section{References}

Alves, P. and Pereira, A.S. (2020) 'Short film production in educational contexts: Exploring the methodology of the Olhar pela Lente project in Portugal'. Film Education Journal, 3 (1), 13-31. https://doi.org/10.14324/FEJ.03.1.02.

Bachmann, A. and Zahn, M. (2018) 'Film education as a multiplicity of practices: A media-ecological perspective'. Film Education Journal, 1 (1), 78-89. https://doi.org/10.18546/FEJ.01.1.07.

BBC (British Broadcasting Corporation) (2019) 'Free iPads for nearly 50,000 school pupils in Glasgow'. 26 August. Accessed 16 February 2021. www.bbc.co.uk/news/uk-scotland-glasgowwest-49475108.

Bergala, A. (2016) The Cinema Hypothesis: Teaching cinema in the classroom and beyond (FilmmuseumSynemaPublikationen 28). Trans. M. Whittle. Vienna: Austrian Film Museum.

BFI (British Film Institute) (2015) 'A framework for film education'. Accessed 16 February 2021. www2.bfi.org.uk/sites/bfi.org.uk/files/downloads/\%20bfi-a-framework-for-film-educationbrochure-2015-06-12.pdf.

Borčić, M. (2020) 'Triangulating a discussion between film, the viewer and a wider frame of life: Reflections on a life in film education'. Film Education Journal, 3 (1), 32-45. https://doi.org/10.14324/FEJ.03.1.03.

Burn, A. and Durran, J. (2007) Media Literacy in Schools: Practice, production and progression. London: Sage.

Chambers, J. (2019) 'Exploring co-creation in practical film education from primary school to postgraduate study: Theoretical and autoethnographic perspectives upon teaching film practice'. Film Education Journal, 2 (1), 27-47. https://doi.org/10.18546/FEJ.02.1.03.

Cooper, S. (2020) How to elements of bathrooms. 13 June. Accessed 18 March 2021. www.youtube. $\mathrm{com} /$ watch? $=$ XGHzK7PQqCs.

Correa, F. (2020) 'Immaterial cultural heritage and a sense of place in film-based art education: A case study of a documentary film project with secondary school children as part of Cine en curso Chile'. Film Education Journal, 3 (2), 123-37. https://doi.org/10.14324/FEJ.03.2.02.

Cousins, M. (2006) '"... And now, it's over?" The problem with Scottish cinema'. The Drouth, 200 (20), 11-22.

Daly, M., Thomson, J. and Chambers, J. (2020) 'Securing a place for film within the ongoing life of a Scottish state secondary school'. Film Education Journal, 3 (2), 160-74. https://doi.org/10.14324/ FEJ.03.2.04. 
Donnelly, P. (n.d.) Educational Attainment Gap - Role of the Third and Private Sectors: Parliamentary Inquiry: Response by Scottish Film. Accessed 12 May 2021. http://archive2021.parliament.scot/ S4_EducationandCultureCommittee/Educational\%20attainment/UNISONScotland2.pdf.

Education Scotland (2021) Animation in the Classroom - Developing skills in animation. Accessed 18 March 2021. https://education.gov.scot/improvement/practice-exemplars/animation-in-theclassroom-developing-skills-in-animation/\#.

Fleer, M. (2018) 'Digital animation: New conditions for children's development in play-based setting'. British Journal of Educational Technology, 49 (5), 943-58. https://doi.org/10.1111/ bjet.12637.

Genazino, W. (2007) 'Der gedehnte Blick'. In W. Genazino, Der gedehnte Blick. München: Deutscher Taschenbuch Verlag, 38-61.

Gunning, T. (1990) 'Cinema of attractions: Early film, its spectator and the avant-garde'. In T. Gunning, T. Elsaesser and A. Barker (eds), Early Cinema: Space-frame-narrative. London: $\mathrm{BFI}, 56-63$.

IPS (Independent Producers Scotland) (2015) IPS Recommendations to SGov: Inquiry into economic impact of Scotland's creative industries. Accessed 12 May 2021. http://archive2021.parliament. scot/S4_EconomyEnergyandTourismCommittee/Inquiries/IPS.pdf.

McArthur, C. (ed.) (1982) Scotch Reels: Scotland in cinema and television. London: BFI.

Murray, J. (2019) 'Trainspotter's delight: Issues and themes in Scottish film criticism'. In J. Hill (ed.), A Companion to British and Irish Cinema. London: Wiley-Blackwell, 490-509.

Pantenburg, V. and Schlüter, S. (2018) 'Teaching experimental film: On the practical and analytic treatment of avant-garde cinema'. Film Education Journal, 1 (2), 115-32. https://doi.org/10.18546/FEJ.01.2.02.

Petrie, D. (2014) 'The eclipse of Scottish cinema'. Scottish Affairs, 23 (2), 217-33. https://doi.org/10.3366/scot.2014.0018. 